\title{
The Africa Regional SGBV Network Learning Brief Series: Learning updates from Kenya (Brief \#2)
}

Population Council

Follow this and additional works at: https://knowledgecommons.popcouncil.org/departments_sbsr-rh

Part of the Demography, Population, and Ecology Commons, Domestic and Intimate Partner Violence Commons, Family, Life Course, and Society Commons, International Public Health Commons, and the Maternal and Child Health Commons

How does access to this work benefit you? Let us know!

\section{Recommended Citation}

"The Africa Regional SGBV Network Learning Brief Series: Learning updates from Kenya (Brief \#2)." Nairobi: Population Council, 2016. 
Population Council

The Africa Regional SGBV Network Learning Brief Series

Fostering a Multisectoral Response to Violence against Children in East and Southern Africa

\section{Learning Updates from Kenya (Brief \#2)}

Data from 130 public health facilities supported by LVCT Health indicate that over $60 \%$ of rape survivors attended to from 2011 to 2014 were children below the age of 18. The Africa Regional Sexual and Gender Based Violence (SGBV) Network, set up in 2006, is addressing violence against children (VAC) in four countries. This Learning Brief is one in a series of five that share critical, initial understandings of VAC that will help us respond more effectively to the problem.

\section{LVCT Health}

LVCT Health is a Kenyan organisation with a goal of reducing HIV infections to zero. It generates evidence for sexual and gender-based violence (SGBV) policy reform and supports the Kenyan government to provide post-rape care services in public hospitals. As a member of the Africa Regional SGBV

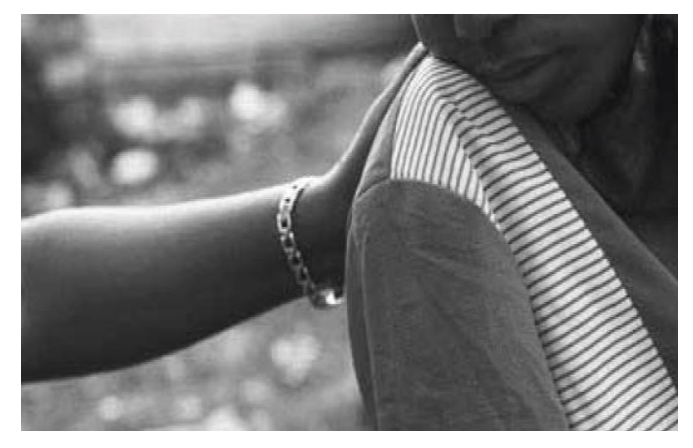
Network, it has found that the majority of those seeking post-rape care

HEALTH CARE PROVIDERS ARE NOT TRAINED TO ATTEND TO CHILD SURVIVORS in two county hospitals (Nakuru and Nyeri) are children. To respond to this demand from girls and boys affected by sexual violence, LVCT Health is exploring the extent to which sexual violence services meet the needs of children in Kenya. Initial findings highlight a postrape care system that is inadequate for children. 


\section{What We're already Learning}

LVCT Health is working with the Ministry of Health to improve children's access to quality and comprehensive post-rape care services. Here's what we're learning about existing care in two county hospitals (Nakuru and Nyeri) for child survivors of rape:

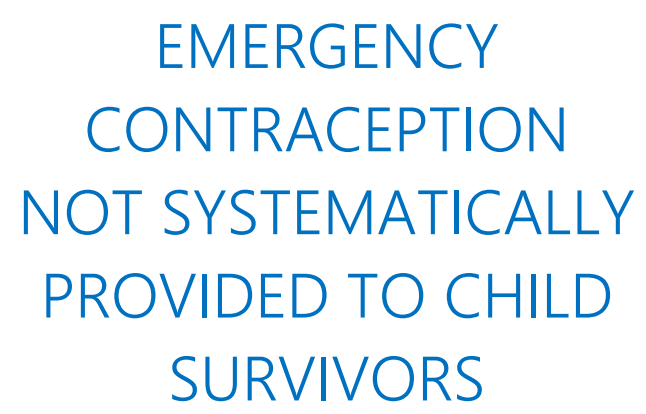

- Health care providers are not equipped to attend to child survivors. Less than $0.5 \%$ of the 518 providers employed by the county hospitals have been trained in the management of child survivors of rape.

- Health systems for survivors are not child-centered, despite the large number of children that seek post-rape care. There are no service delivery charters or standard operating procedures to guide providers regarding children.

- There are no written materials available for children or their caregivers on what care is available to them within and outside health facilities. They need to be made aware that, as survivors of sexual assault, there's a range of health services available to them. They need to know that they may have to return to the health facility a number of times to access everything they need.

- Emergency contraception is not systematically provided to child survivors; yet, $16 \%$ of such survivors were documented as being pregnant at the time of seeking post-rape care at the two county hospitals.

- Comprehensive post-rape care services are currently offered over a series of hospital visits. Children survivors rarely manage to make all the visits and miss out on essential treatment and care. Mechanisms for overcoming this barrier are required.

- Child survivors of rape are more likely to seek timely medical care if the perpetrator is unknown to them. We need to look into how to address the issue of children reporting rape by someone they know.

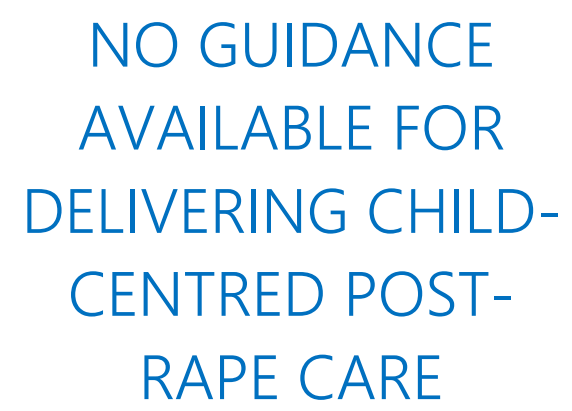




\section{What We're Doing about It}

From 2016-2017, LVCT Health is testing the feasibility of a response model that includes:

- the development and implementation of standard operating procedures for managing child survivors at health facilities

- child-centred training for providers

- child survivors being assigned case managers who will ensure they access all the post-rape care services they need

Since 2006, the Africa Regional SGBV Network has worked to build effective responses to SGBV in low-resource settings, focusing on those who have experienced violence, as well as on violence prevention. From 2014-2017, the network is addressing the needs of two vulnerable populations - children and refugees.

(c) 2016 The Population Council, Inc.

Network Contact:

Population Council

General Accident Insurance House

Ralph Bunche Road

Nairobi, Kenya

T: + 254202713480

E: info.nairobi@popcouncil.org
LVCT Health Contact:

Off Argwings Kodhek Road

Olympia Park

Nairobi, Kenya

T: +254202646692

E: cajema@lvcthealth.org. Idigolo@Ivcthealth.org

We gratefully acknowledge the support of the Regional Team for Sexual and Reproductive Health and Rights, Embassy of Sweden, Lusaka, Zambia.

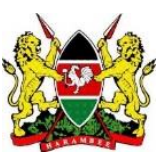

